\title{
Should accident and emergency nurses request radiographs? Results of a multicentre evaluation
}

\author{
John Thurston, Stuart Field, on behalf of a Working Party
}

British Association for Accident and

Emergency Medicine, Royal College of Surgeons, Lincoln's Inn Fields, London

WC2, United Kingdom J Thurston

Royal College of Radiologists,

Portland Place,

London W1,

United Kingdom

Stuart Field

Working Party

J Thurston MB, FRCP,

FFAEM

A Charlett MSc

$S$ Davies HDCR

$S$ Field MA, FRCR

G Hughes DRCOG,

MRCP, FFAEM

G Jones RGN OND

Dip.N (Lond), FETC

$\mathrm{K}$ Little MD, FRCP,

FRCSEd, FFAEM

Correspondence to:

Dr John Thurston

Queen Mary's University

Hospital, Roehampton Lane,

London SW 15 5PN.

\begin{abstract}
Objective-To evaluate whether waiting time in accident and emergency (A\&E) departments is shortened when experienced nurses request peripheral limb radiographs before a patient is assessed by a doctor.

Design-Simultaneous prospective trial in four A\&E departments in the United Kingdom with doctors and nurses requesting radiographs; 2000 patients were randomly allocated to either a "Nurse First" or "Doctor First" category.

Subjects-Patients older than 5 years presenting with recent peripheral limb injuries.
\end{abstract}

Main outcome measures-Timing of the various stages of a patient's passage through the A\&E department comparing the orthodox route with a group of patients in whom an experienced $A \& E$ nurse had the option of requesting a radiograph before a medical assessment.

Results-There was a significant reduction in the time spent in $A \& E$ when no radiograph was requested $(P \ll 0 \cdot 001)$. The mean time saved in the "Doctor First" (DF) group was $51 \mathrm{~min}$, and in the "Nurse First" (NF) group $36 \mathrm{~min}$. For those who were sent for an $x$ ray $14 \mathrm{~min}$ was saved by getting the patient to see the nurse first. However, because the overall referral rate for $x$ rays was greater in the NF group, (78\% of patients compared with $74 \%$ of the DF group, a significant $4 \%$ increase $(P=0.05)$ this potential benefit was largely lost. Overall the average waiting time in the DF group of $92.5 \mathrm{~min}$ (95\% confidence interval: 89.2 to $96.1 \mathrm{~min}$ ) was reduced to $88 \cdot 5 \mathrm{~min}(95 \% \mathrm{CI}: 85 \cdot 2$ to $91.8 \mathrm{~min}$ ) in the NF group, a non-significant saving of $4 \mathrm{~min}$. There was no overall difference between the proportion of relevant abnormalities reported by the radiologists for the $\mathrm{DF}$ or $\mathrm{NF}$ groups (G2 = 0.739, 1df, $P=0 \cdot 30)$; however, there was a significant association between the number of relevant abnormalities reported by the radiologists and the different hospitals (G2 $=9.7626,3 \mathrm{df}, P=0.02$ ). Hospital $C$ had the highest abnormality rate reported by the radiologists in both the DF $(45 \%)$ and the NF $(51 \%)$ groups. The most time saved in A\&E was in the DF category when comparing those who did not have an $x$ ray [58 (CI 54-63) min] with those who did [109 (CI 104-i14) min], a saving of $51 \mathrm{~min}$. The corresponding time saved in the NF category between those who did not have an $x$ ray [59 (CI 53-65) min] and those who did [95 (CI 91-99) min] was $36 \mathrm{~min}$.

Conclusions-14 min can be saved by getting the patient to see the nurse first; however, because nurses in three out of four hospitals requested more radiological examinations than doctors, overall only 4 min waiting time was saved when peripheral limb radiographs were requested by nurses. The findings are somewhat against expectations but do identify that specific training and constant monitoring is essential if nurses are to request peripheral limb radiographs, as reflected in hospital $\mathrm{C}$ results.

(f Accid Emerg Med 1996;13:86-89)

Key terms: $x$ rays; $A \& E$ department; $A \& E$ nurses; $A \& E$ doctors; waiting time

It has been suggested that waiting time in accident and emergency (A\&E) departments may be reduced if triage is undertaken by a nurse of suitable experience and training, who also has the authority to request selective radiographs. ${ }^{1-4}$ A working party from interested Royal Colleges and Associations was established in order to evaluate this suggestion. A protocol was developed, and a trial carried out in four $A \& E$ departments in the United Kingdom.

The four A\&E departments were in (1) an inner city university teaching hospital where 50000 new patients are seen annually with an average waiting time of two to three hours; (2) an outer London university teaching hospital where 43000 new patients are seen annually with an average waiting time of two hours; (3) a large capital city teaching hospital where 86000 new patients are seen annually with a waiting time of up to three hours; and (4) a district general hospital outside Manchester city centre seeing 55000 new patients annually with a mean waiting time for all patients of 46 minutes.

\section{Methods}

On presentation at $A \& E$ reception, patients with recent peripheral limb injuries were assessed by a triage nurse and, if appropriate, entered into the trial. Inclusion criteria were that the injury should have occurred within the previous 24 hours and be at the elbow or distal to it, or at the knee or distal to it. Patients with other injuries, or who were aged 5 years or less, were excluded. Consecutively presenting 
patients at four hospitals were entered into the study. Each patient was randomly allocated for examination either by a doctor ("Doctor First", DF) or for assessment by an experienced $A \& E$ nurse of $F$ grade or above who had been specifically trained in the indications for referral for radiological examination ("Nurse First", NF). Each A\&E consultant agreed to train the nurses appropriately, but it was left to the individual consultants to do it in their own way. There was no agreed protocol for training. The randomised allocation was performed using a randomisation list produced by a pseudo random number generator. This list was held at the main $A \& E$ reception and the receptionist entered the patients consecutively on this list and allocated a colour coded form to the patient.

A sample size of 500 subjects per hospital was considered adequate to provide sufficient power to detect as statistically significant any clinically worthwhile differences in the average time spent in $A \& E$. It was thought sufficient to detect any important differences in the proportion of referrals between the two groups. If the patient was allocated to the NF group, the nurse would determine whether or not a radiograph was required by making four observations: the presence of swelling, bony tenderness, deformity at the site of injury, or the suspicion of a foreign body. Appropriate patients were referred by the nurse or doctor to the $\mathrm{x}$ ray department. If the radiographer considered that the nurse had requested views of the wrong area, then those which were considered by the radiographer to be more appropriate were obtained. The time taken for each stage of the patient's passage through the $\mathrm{A} \& \mathrm{E}$ and $\mathrm{x}$ ray departments was recorded. All patients were seen by a doctor before discharge, including all those who had been triaged by a nurse.

\section{STATISTICAL METHODS}

Log-linear modelling 5 was used to assess the association between categorical variables. Likelihood ratio test statistics (G2) were used to assess the goodness of fit of a particular model and to evaluate the associations.

The total time spent by the patients in the $\mathrm{A} \& \mathrm{E}$ department has been used as the dependent variable in an analysis of variance performed using the GLIM release 3.77 program. Because the distribution of times is positively skewed, a logarithmic transformation of the total time was employed before the analysis of variance was performed; hence the average waiting times are expressed as geometric means.

\section{Results}

There were a total of 92 ineligible case record forms and 75 missing forms, leaving a total of 1833 patients in the trial (table 1). Ineligible forms included either patients with multiple injuries, others wrongly entered into the trial, or those patients who discharged themselves from hospital before they had been completely assessed. The numbers of patients initially referred for radiography are shown in table 2 .
Table 11833 AE E attenders randomised to be seen by $a$ doctor or a nurse first in four different hospitals

\begin{tabular}{lllllr}
\hline Patient group & \multicolumn{2}{l}{ Hospital } & Total \\
\cline { 2 - 5 } & $A$ & $B$ & $C$ & $D$ & \\
\hline Doctor first & 229 & 241 & 220 & 228 & 918 \\
Nurse first & 238 & 238 & 214 & 225 & 915 \\
Total & 467 & 479 & 434 & 453 & 1833 \\
\hline
\end{tabular}

The referral rates between the NF and DF groups were significantly different between each hospital ( $\mathrm{G} 2=12.009,3 \mathrm{df}, \mathrm{P} \ll 0.001$ ), the difference being maximal in hospital $\mathrm{B}$ where $10 \%$ more patients had radiographs when they were requested by a nurse. In hospitals $\mathrm{A}, \mathrm{B}$, and $\mathrm{D}$ nurses requested more radiographs than the doctors. In hospital $\mathrm{C}$ nurses requested $8 \%$ fewer radiographs than the doctors. Overall $78 \%$ were referred for radiographs in the NF group, compared with $74 \%$ in the DF group. This $4 \%$ difference is statistically significant $(P=0.05)$. Hospitals $A$, $\mathrm{B}$, and $\mathrm{D}$ had similar overall referral rates for radiography (around $80 \%$ of all patients entered into the trial). In hospital $\mathrm{C}$ the overall referral rate was $62 \%$. This lower rate of referral at hospital $\mathrm{C}$ occurred in both the $\mathrm{DF}$ and NF groups.

As part of the trial the radiographers assessed whether they thought that the area designated for radiography was appropriate for the site of injury. If it was not, they were instructed to take what they deemed to be the appropriate radiograph. Using this criterion the nurses requested $3.2 \%$ more inappropriate areas than the doctors $(95 \%$ confidence interval $5 \cdot 2 \%$ to $0.9 \%, \mathrm{P}=0.005)$. The results of the $x$ ray reports from the radiologists are shown in table 3. An "abnormal" report was defined as one where there was a pathological finding relevant to the presenting symptom.

A total of 281 patients from the four hospitals allocated to the NF group were not initially sent for radiography; 66 of these $281(23.5 \%)$ were subsequently sent for radiography by the $\mathrm{A} \& \mathrm{E}$ doctor. Twenty one of these $(31 \cdot 8 \%)$ had a relevant abnormality revealed by the radiograph. These abnormalities included:

- Fracture phalanx of finger or toe

- Fractured metacarpal or metatarsal

- Elbow effusion

- Avulsion fracture ankle

- Avulsion fracture lunate

- Others

(includes loose body in knee, knee effusions, and infected $\mathrm{K}$ nail)

At the bottom of table 6 is given the number of patients in each hospital in whom a nurse did not request a radiograph but a doctor subsequently did. It can be seen that in hospital C

Table 21388 patients referred from $A \mathcal{E} E$ for radiography. The percentage of patients radiographed as a proportion of total attenders at each hospital is shown in brackets

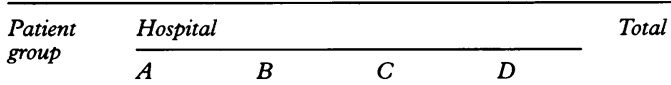

Doctor first $172(75 \%) \quad 179(74 \%) \quad 144(65 \%) \quad 182(80 \%) \quad 677$ Nurse first $194(82 \%) \quad 199(84 \%) \quad 123(57 \%) \quad 195(87 \%) \quad 711$ Total $\quad 366(78 \%) \quad 378(79 \%) \quad 267(62 \%) \quad 377(83 \%) \quad 1388$ 
Table 3 Results of the $x$ ray reports from the radiologist. An "abnormal" report was defined as one where there was a pathological finding relevant to the presenting symptom

\begin{tabular}{|c|c|c|c|c|c|c|}
\hline \multirow[t]{2}{*}{ Patient group } & \multirow[t]{2}{*}{$x$ ray report } & \multicolumn{4}{|l|}{ Hospital } & \multirow[t]{2}{*}{ Total } \\
\hline & & $A$ & $B$ & $C$ & $D$ & \\
\hline Docto & $\begin{array}{l}\text { Abnormal } \\
\text { Normal }\end{array}$ & $\begin{array}{l}73(43 \%) \\
97(57 \%)\end{array}$ & $\begin{array}{r}70(40 \%) \\
106(60 \%)\end{array}$ & $\begin{array}{l}64(45 \%) \\
78(55 \%)\end{array}$ & $\begin{array}{r}69(38 \%) \\
113(62 \%)\end{array}$ & $\begin{array}{l}276(41 \%) \\
394(59 \%)\end{array}$ \\
\hline Nurse first & $\begin{array}{l}\text { Abnormal } \\
\text { Normal }\end{array}$ & $\begin{array}{r}75(39 \%) \\
118(61 \%)\end{array}$ & $\begin{array}{r}73(37 \%) \\
126(63 \%)\end{array}$ & $\begin{array}{l}61(51 \%) \\
59(49 \%)\end{array}$ & $\begin{array}{r}65(34 \%) \\
127(66 \%)\end{array}$ & $\begin{array}{l}274(39 \%) \\
430(61 \%)\end{array}$ \\
\hline
\end{tabular}

Table 4 Breakdown of median times in minutes (and interquartile range) in $A \mathcal{E} E$ when an $x$ ray is requested

\begin{tabular}{|c|c|c|c|}
\hline imes & Doctor first & Nurse first & $\begin{array}{l}\text { NF doctor } \\
\text { request }\end{array}$ \\
\hline $\begin{array}{l}\text { Presentation until seen } \\
\text { by nurse } \\
\text { Seen by nurse until } x \text { ray } \\
\text { request received } \\
x \text { ray request received } \\
\text { until } x \text { ray completed } \\
x \text { ray completed until } \\
\text { discharge }\end{array}$ & $\begin{array}{l}10 \\
(5 \text { to } 17) \\
51 \\
(27 \text { to } 100) \\
10 \\
(5 \text { to } 15) \\
23 \\
(15 \text { to } 40)\end{array}$ & $\begin{array}{l}10 \\
(6 \text { to } 17) \\
11 \text { to } 18) \\
(70 \\
(6 \text { to } 15) \\
48 \\
(27 \text { to } 101)\end{array}$ & $\begin{array}{l}10 \\
(6 \text { to } 16) \\
41 \\
(21 \text { to } 75) \\
7 \\
(5 \text { to } 14) \\
34 \\
(22 \text { to } 55)\end{array}$ \\
\hline
\end{tabular}

Table 5 Breakdown of median times in minutes (and interquartile range) in $A \mathcal{E} E$ when no $x$ ray is requested

\begin{tabular}{lll}
\hline Breakdown of times & Doctor first & Nurse first \\
\hline Presentation until seen by & 8 & 8 \\
nurse & $(5$ to 14$)$ & $(5$ to 13$)$ \\
Time seen by nurse until seen & 35 & 44 \\
by doctor & $(13$ to 82$)$ & $(15$ to 75$)$ \\
Time seen by doctor until & 10 & 8 \\
discharge & $(5$ to 15$)$ & $(5$ to 14$)$ \\
\hline
\end{tabular}

there were more patients in this category than in any of the other three hospitals. Patients in hospital $\mathrm{C}$ who were initially triaged by a nurse subsequently therefore had a greater chance of being referred for an $x$ ray by the doctor than in the other three hospitals. As these patients were all seen subsequently by the doctor, and their injuries correctly identified, no harm came to any of the patients as a result of this practice. A breakdown of the times spent in the A\&E departments when a radiograph was requested is given in table 4 and when one was not requested, in table 5 . The times are all shorter when no radiograph was requested.

Table 6 gives the average total time spent by the patient in the $A \& E$ department. This is graphically represented in the figure. It will be seen that there is a slight discrepancy between the totals represented in tables 1 and 6 . This is because 31 subjects had to be omitted from the analysis of the time spent in $A \& E$ because the time had been left blank on the forms returned.

Table 6 Average time and 95\% confidence intervals in minutes spent in each of the four hospitals by attenders in the AGE department, related to each arm of the trial. (The third figure in each entry is the number of patients in the group.)

\begin{tabular}{|c|c|c|c|c|c|}
\hline \multirow[t]{2}{*}{ Patient group } & \multicolumn{4}{|l|}{ Hospital } & \multirow{2}{*}{$\begin{array}{l}\text { All } \\
\text { hospital average }\end{array}$} \\
\hline & $A$ & $B$ & $C$ & $D$ & \\
\hline $\begin{array}{l}\text { Doctor } 1 \mathrm{st}, \\
x \text { rayed }\end{array}$ & $\begin{array}{l}106 \\
97,116 \\
(n=169)\end{array}$ & $\begin{array}{c}99 \\
91,108 \\
(n=175)\end{array}$ & $\begin{array}{l}95 \\
86,105 \\
(n=143)\end{array}$ & $\begin{array}{r}137 \\
126,150 \\
(n=177)\end{array}$ & $\begin{array}{r}109 \\
104,114 \\
(\mathrm{n}=664)\end{array}$ \\
\hline $\begin{array}{l}\text { Doctor } 1 \mathrm{st} \\
\text { no } x \text { ray }\end{array}$ & $\begin{array}{r}65 \\
56,750 \\
(n=57)\end{array}$ & $\begin{array}{r}42 \\
37,490 \\
(n=60)\end{array}$ & $\begin{array}{r}55 \\
48,620 \\
(n=76)\end{array}$ & $\begin{array}{r}89 \\
75,106 \\
(n=44)\end{array}$ & $\begin{array}{r}58 \\
54,630 \\
(n=237)\end{array}$ \\
\hline $\begin{array}{l}\text { Nurse } 1 \mathrm{st}, \\
x \text { rayed }\end{array}$ & $\begin{array}{c}93 \\
86,101 \\
(n=194)\end{array}$ & $\begin{array}{c}91 \\
84,980 \\
(n=195)\end{array}$ & $\begin{array}{c}68 \\
62,760 \\
(n=122)\end{array}$ & $\begin{array}{r}122 \\
113,132 \\
(n=192)\end{array}$ & $\begin{array}{r}94 \\
90,980 \\
(n=703)\end{array}$ \\
\hline $\begin{array}{l}\text { Nurse } 1 \text { st, } \\
\text { no } x \text { ray }\end{array}$ & $\begin{array}{c}67 \\
54,820 \\
(n=28)\end{array}$ & $\begin{array}{r}50 \\
39,640 \\
(n=22)\end{array}$ & $\begin{array}{c}53 \\
46,610 \\
(n=63)\end{array}$ & $\begin{array}{c}86 \\
66,111 \\
(n=19)\end{array}$ & $\begin{array}{r}59 \\
53,650 \\
(n=132)\end{array}$ \\
\hline $\begin{array}{l}\text { Nurse } 1 \mathrm{st}, \\
\text { doctor later made } \\
x \text { ray request }\end{array}$ & $\begin{array}{r}87 \\
66,115 \\
(n=16)\end{array}$ & $\begin{array}{c}114 \\
82,158 \\
(n=12)\end{array}$ & $\begin{array}{c}94 \\
76,117 \\
(\mathrm{n}=27)\end{array}$ & $\begin{array}{r}123 \\
88,172 \\
(n=11)\end{array}$ & $\begin{array}{r}100 \\
87,115 \\
(\mathrm{n}=66)\end{array}$ \\
\hline
\end{tabular}

The average waiting time in the DF group was $92.5 \mathrm{~min}$ and in the NF group $88.5 \mathrm{~min}$. The average saving of $4 \mathrm{~min}$ is not statistically significant $(P=0 \cdot 1)$.

\section{SUMMARY OF FINDINGS}

(1) There was a significant reduction in the time spent in $A \& E$ when no radiograph was requested $(P \ll 0.001)$. The average time saved in the "Doctor First" group was $51 \mathrm{~min}$, and in the "Nurse First" group $36 \mathrm{~min}$. (2) There was a significant difference in the time spent in the $A \& E$ departments between the different hospitals $(P \ll 0.001)$ whether or not the patient was referred for radiography. (3) Patients in the NF group passed through the A\&E departments slightly more quickly. Overall only 4 min were saved if a nurse saw the patient first. This saving was not significant $(P=0 \cdot 1)$. However, when no radiograph was performed there was no difference in waiting times between patients initially assessed by a doctor or nurse. When a radiograph was taken 14 min was saved on average in the NF group.

\section{Discussion}

This study shows that the four minutes of overall waiting time saved if nurses are allowed to request radiographs is trivial compared with the total time spent in $A \& E$. However, if a patient who attends an $A \& E$ department needs a radiograph as part of their management, 14 minutes waiting time can be saved if the request for the radiograph is made by a nurse who performs the initial triage. However, because nurses overall requested more $\mathrm{x}$ rays this potential benefit was almost completely lost. If radiography is not required, then there is no overall reduction in waiting time as a result of nurse triage.

Several potential disadvantages were revealed as a result of nurses requesting radiography. Overall nurses requested $4 \%$ more radiographs than doctors. This has been shown before. ${ }^{3}$ Furthermore, nurses requested more radiographs of inappropriate areas than the doctors. However, some of the inappropriate requests arose because nurses requested radiographs of the wrist when querying a fracture of the scaphoid, not appreciating that additional scaphoid views were necessary. However, the results from hospital $\mathrm{C}$, where nurses had the lowest overall referral rate and the highest detection rate, show that with good training there is potential to overcome the disadvantages which were revealed in this study as a result of nurses requesting radiography.

It is recommended that practices in hospital $\mathrm{C}$ be researched in order to evaluate whether they can be replicated cost-effectively. Such practices could clearly result in time and radiation dose savings. Although not part of the prime objective of this trial, the small group of patients seen initially by a nurse, but not sent for an $x$ ray, and who were subsequently found to have a relevant abnormality, suggests that it is essential for all patients, where an emergency nurse practitioner scheme is not in operation, to be seen by a doctor, even if they are initially triaged by a nurse. 


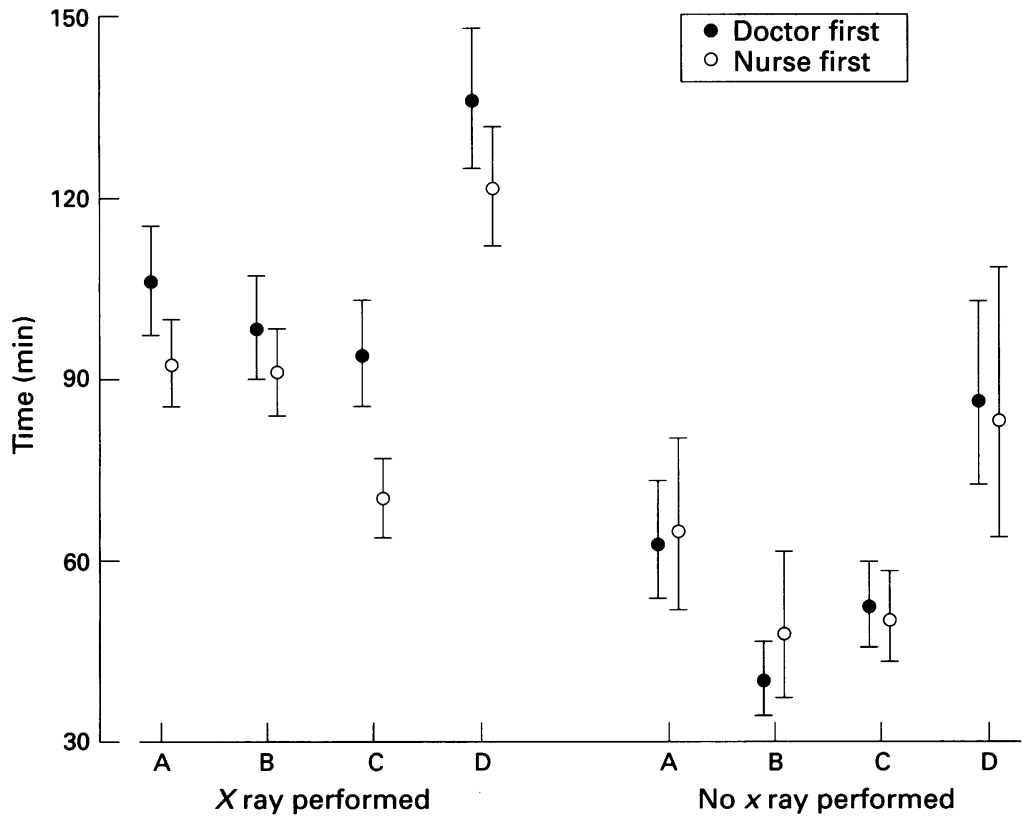

Average time (min) spent in each of four accident and emergency departments $(A, B, C, D)$.

The small waiting time saved by an initial nurse triage must be set against a background of a considerable variation in waiting times between different hospitals. These individual differences in waiting times are nearly 13 times greater than the overall four minutes saved when patients were triaged by a nurse.

The greatest saving in waiting time was between those patients who did not have a radiograph compared with those who did, irrespective of whether they were seen initially by a nurse or a doctor. In one hospital (C), however, nurses referred $8 \%$ fewer patients for radiography than doctors, and also had the highest abnormality detection rate. Potential time savings here were therefore much greater. Close enquiry revealed that the A\&E consultant at this hospital had spent considerably longer training his nurses in the indications for radiography compared with the other hospitals. This additional emphasis on training might also be a factor in the lower referral rate from the doctors in this hospital compared with the others.

In the individual hospital the single most important factor in patient waiting time was whether or not a radiograph was requested.

The overall referral rate in this study was relatively high with 60 to $80 \%$ of patients being radiographed. The authors have been unable to find comparative referral rates for these types of injury in published reports. However, one of us (SF) ran a computer program for his own hospital during the six months between January and May 1992 and revealed a referral rate of $37 \%$. In a large multicentre study, ${ }^{7}$ this hospital was found to have one of the lowest clinically unsuspected fracture rates in the arm, and yet one of the highest overall percentages of radiologically detected fractures. ${ }^{8}$ This shows that a low referral rate for radiological examination does not necessarily mean that important injuries are missed.

If $x$ ray referral rates for nurses can be kept the same as for doctors in the same establishment then overall waiting times will be reduced. If referral rates are high, retraining of doctors and nurses is needed, emphasising guidelines on the clinical indications for referral for radiological investigation. This would have a much more significant effect on patient waiting time than nurse triage alone. This would not only reduce unnecessary radiography, but it would also reduce the radiation dose to individuals and the population, as well as saving staff time and money.

\section{CONCLUSIONS}

The interhospital variation in referral rates for radiographic examination suggests that adequate time should be spent on proper training of nurses and doctors emphasising the clinical criteria for radiological examination. The results of this trial indicate that: (1) patients spend much less time waiting in $A \& E$ departments if they do not have a radiograph taken; (2) nurses are more likely than doctors to refer $\mathrm{A} \& \mathrm{E}$ patients for radiological examination, and as a result the potential saving of 14 minutes, when a nurse requests a radiograph, is reduced to four minutes when patients are reviewed overall; (3) nurses make slightly more requests for inappropriate areas than doctors; (4) there was a large interhospital variation in the $x$ ray referral rates; $(5)$ we believe that in view of the wide interhospital variation, monitoring of $x$ ray referral rates before and after $x$ ray triage by nurses, if introduced, should be mandatory; (6) the results from hospital $\mathrm{C}$ emphasise the importance of radiological training and the provision of appropriate guidelines before this practice is introduced.

This study was supported by a grant from the British Association for Accident and Emergency Medicine, the College of Radiographers, the Royal College of Radiologists, and the A\&E Association of the Royal College of Nursing. The opinions expressed herein are those of the individuals on the Working Party, and not necessarily those of the organisation that they represent. The College of Radiographers also made a valuable copresent. The College of Radiographers airo

The Working Party would like to thank Mrs Julia Kirk for her pains Wing typing of this manuscript, and Dr Gerald de Lacey painstaking typing of this manuscript, and Dr Gerald de Lacey of Northwick Park Hospital for his enthusiastic help in the
design of the trial and helpful comments on the manuscript.

1 Yates D. Nurse practitioners for Accident and Emergency? Br f Accid Emerg Med 1987;2:10-11.

2 Head S. Nurse practitioners: the new pioneers. Nursing Times 1988; 29 June: $27-8$.

3 James MR, Pyrgos N. Nurse practitioners in the Accident and Emergency department. Arch Emerg Med 1989: 6:241-6

4 Macleod AJ, Freeland P. Should nurses be allowed to request X-Rays in an Accident and Emergency Department? Arch Emerg Med 1992;9:19-22.

5 Bishop YMM, Fienburg SE, Holland PW. Discrete multivariate nnalysis, theory and practice. Cambridge, MA: MIT Press, 1975.

6 Payne CD, ed. The GLIM system, release 3.77. Generalised linear interactive modelling manual. Oxford: Numerical Algorithms Groups, 1986.

7 Royal College of Radiologists Working Party. Radiography of injured arms and legs in eight accident and emergency units in England and Wales. BMF 1985;291:1325-8.

8 Stuart Field, EP Abson, SC Brooks. Radiography of injured arms and legs in eight accident and emergency units in England and Wales. BMF 1985;291:1648. 